\title{
The amount of shade influences the behavior and physiology of dairy cattle
}

\author{
K. E. Schütz, ${ }^{* 1}$ A. R. Rogers, ${ }^{*}$ Y. A. Poulouin, ${ }^{*} \dagger$ N. R. Cox, ${ }^{*}$ and C. B. Tucker $\ddagger$ \\ ${ }^{*}$ AgResearch Ltd., Private Bag 3123, Hamilton 3240, New Zealand \\ †University of South Brittany, Rue Yves Mainguy, 56000 Vannes, France \\ fDepartment of Animal Science, University of California, 1 Shields Ave, Davis 95616
}

\section{ABSTRACT}

The objective was to understand how the amount of shade (shade cloth blocking $99 \%$ of solar radiation) influenced the behavior and physiology of HolsteinFriesian dairy cattle managed on pasture. We compared behavior, body temperature, and respiration rate of cattle provided with 1 of 3 treatments for $5 \mathrm{~d}$ : access to $2.4 \mathrm{~m}^{2}$ or $9.6 \mathrm{~m}^{2}$ shade/cow, or no shade $(\mathrm{n}=4$ groups/treatment, 10 animals/group). Behavioral observations were carried out between 1000 and $1550 \mathrm{~h}$. Cows spent more than twice as much time in the larger shade (24 vs. $50 \%$ of observations for $2.4 \mathrm{~m}^{2}$ and 9.6 $\mathrm{m}^{2}$ shade/cow, respectively, SED: $1.7 \%$ ) and engaged in fewer aggressive interactions when more shade was provided (10.7 vs. 3.2 aggressive interactions $/ \mathrm{m}^{2}$ during $5.8 \mathrm{~h}$ of observation for $2.4 \mathrm{~m}^{2}$ and $9.6 \mathrm{~m}^{2}$ shade/cow, respectively, SED: 3.16 interactions $/ \mathrm{m}^{2}$ ). Time around the water trough increased when little or no shade was provided (11, 5 , and $2 \%$ of observations within $4.5 \mathrm{~m}$ of water trough for no shade, $2.4 \mathrm{~m}^{2}$, and $9.6 \mathrm{~m}^{2}$ shade/ cow, SED: $2.4 \%$ ). Respiration rate was higher when cows had less shade available $(62,57$, and 51 breaths/ min for no shade, $2.4 \mathrm{~m}^{2}$, and $9.6 \mathrm{~m}^{2}$ shade/cow, respectively, SED: 2.1 breaths/min). All cows used the shade more when $9.6 \mathrm{~m}^{2}$ shade/cow was provided; simultaneous use was observed in 15 versus $0 \%$ of observations in the $9.6 \mathrm{~m}^{2}$ and $2.4 \mathrm{~m}^{2}$ treatments on the warmest day, respectively. Weather conditions influenced both the behavioral and physiological responses, and these changes were more pronounced when less or no shade was available. Cows spent more time in shade and less time lying with increasing heat load. In addition, aggressive interactions in the shade, time around the water trough, mean body temperature, and respiration rate increased with environmental heat load. Our findings highlight the importance of determining and providing an effective amount of shade to cattle.

Key words: behavior, dairy cattle, physiology, shade

Received May 24, 2009.

Accepted September 16, 2009.

${ }^{1}$ Corresponding author: Karin.schutz@agresearch.co.nz

\section{INTRODUCTION}

Exposure to summer weather affects both the behavior and physiology of cattle and can impair animal welfare. Increased heat load, caused by a combination of air temperature, relative humidity, air movement, and solar radiation, increases body temperature and respiration rate and can reduce feed intake and milk and meat production (Hahn, 1999; Ominski et al., 2002; West, 2003). Excessive heat load can negatively affect breeding performance in dairy cattle by reducing fertility (Roman-Ponce et al., 1977; De Rensis and Scaramuzzi, 2003) and can, in extreme cases, result in death (Armstrong, 1994).

Cows readily use shade when given access to it, and the provision of shade can alleviate negative effects of increased heat load (Roman-Ponce et al., 1977; Valtorta et al., 1997). Dairy cattle are highly motivated to use shade in warm weather (Schütz et al., 2008). Furthermore, there is anecdotal evidence that cattle will engage in aggressive behavior to gain access to shade. Cows will spend more time in shade as ambient air temperature and solar radiation increase (Kendall et al., 2006), indicating that shade becomes more important in warmer environmental conditions. Unshaded cattle adopt other behavioral strategies, such as increasing the time around the water trough and more time standing in response to heat load (Ansell, 1981; Mader et al., 1997; Widowski, 2001).

Few studies have directly compared the effects of the amount of shade in controlled experiments and these studies often focused on production traits including weight gain, milk production, and reproductive efficiency of shaded versus unshaded groups of cattle. These studies recommend between 3.5 and $5.6 \mathrm{~m}^{2}$ shade/cow for dairy cattle (Buffington et al., 1983; Collier et al., 2006) and 2.3 to $5.6 \mathrm{~m}^{2}$ shade/cow for beef cattle (Ittner et al., 1954; Garrett et al., 1962). There is some evidence that changes in production may be relatively "downstream" indicators of heat stress compared with the immediate physiological responses such as respiration rate. For example, Mader et al. (1997) demonstrated that animals with access to $3.5 \mathrm{~m}^{2}$ shade/animal had higher feed intake and lower respira- 
tion rates than animals with less shade, but found no difference in weight gain.

Changes in production can be useful to determine when an animal is unable to adapt to a situation. If the environment allows it, an animal will change its behavior to cope with the situation well before production is compromised. Therefore, behavior can provide insight into how animals immediately respond to environmental conditions, making it a useful tool for examining the effect of specific design features of shade. Although no work has directly examined the effect of the amount of shade on behavior, groups of dairy cattle will simultaneously use this resource, especially when solar radiation levels are highest (Tucker et al., 2008). These results indicated that shade might need to be large enough for all cows to use it at the same time.

In this experiment, the aim was to understand how the amount of shade influenced the physiological and behavioral responses of dairy cattle under a range of environmental conditions. Cows given more shade were predicted to show fewer behavioral and physiological responses to increased heat load, spend more time in the shade, have lower respiration rates and lower body temperatures, and spend less time around the water trough and less time standing than cows with less or no shade. Similarly, fewer aggressive interactions and more simultaneous use of shade among cows with more shade compared with those with less shade were predicted.

\section{MATERIALS AND METHODS}

\section{Animals and Treatments}

All procedures involving animals were approved by the Ruakura Animal Ethics Committee under the NZ Animal Welfare Act 1999. One hundred twenty Holstein-Friesian dairy cows were used. The cows were in mid-lactation, ranged from 3 to $13 \mathrm{yr}$ of age, and were $170 \pm 19$ (mean \pm SD) DIM at the beginning of the experiment. The animals had a BW of $494 \pm 66$ $\mathrm{kg}$. Milk production at the start of the experiment was $19.3 \pm 3.6 \mathrm{~kg} / \mathrm{d}$.

The animals were grazed as 12 groups (10 cows/ group) at AgResearch farms near Hamilton, New Zealand (latitude $37^{\circ} 47^{\prime} \mathrm{S}$, longitude $175^{\circ} 19^{\prime} \mathrm{E}$ ). Treatment groups were formed $2 \mathrm{~d}$ before the start of observations. During this 2-d acclimation period, cows were kept with the same shade structures used during observations. The treatment groups were balanced for milk production. Silage (approximately 14 to $16 \mathrm{~kg}$ of DM/ cow, 11 to $12 \mathrm{MJ} / \mathrm{kg}$ of DM) and a fresh sward of grass were provided each day immediately after the morning milking. The ratio of grass to silage varied from day to day, depending on grass availability. Cows were milked twice daily at approximately 0630 and 1600 h. Each group was assigned to 1 of 3 treatments: 1) no shade, 2 ) access to a small shade $\left(2.4 \mathrm{~m}^{2}\right.$ shade/cow $)$, and 3$)$ access to a large shade $\left(9.6 \mathrm{~m}^{2}\right.$ shade/cow; $\mathrm{n}=4$ groups per treatment, 10 cows/group). Three groups of cows (1 of each treatment) were tested simultaneously for $5 \mathrm{~d}$, resulting in $20 \mathrm{~d}$ of data collection during February 2007 (Southern Hemisphere summer). Cows always had visual and auditory contact with animals in the other treatments. Shade was provided to 8 groups with wooden shade structures (height: $2.3 \mathrm{~m}$, length: $4.0 \mathrm{~m}$, width: $3.0 \mathrm{~m}$ ). Individual structures were placed side by side to form 1 larger rectangular structure $(4 \times 6 \mathrm{~m}$ for the $2.4 \mathrm{~m}^{2}$ shade/cow treatment and $8 \times 12 \mathrm{~m}$ for the $9.6 \mathrm{~m}^{2}$ shade/cow treatment). The structures were all oriented with the shorter side facing north. The shade structures were covered with shade cloth that blocked 99\% of ambient solar radiation (Donaghys Industries Ltd., Christchurch, New Zealand). The shade treatments had a mowed patch of grass $\left(2.4 \mathrm{~m}^{2}\right.$ shade/cow: $5 \times 7 \mathrm{~m}$ or $9.6 \mathrm{~m}^{2}$ shade/cow: $9 \times 13 \mathrm{~m}$ ) that contained a painted rectangle directly beneath the structures to facilitate behavioral observations. To create grazing areas that were the same size in all treatments, grass along the fence lines in the $2.4 \mathrm{~m}^{2}$ shade and no-shade treatments was mown to equal the area cut under the shade structure in the $9.6 \mathrm{~m}^{2}$ shade/cow treatment. The water trough ( 1 in each treatment, height: $0.5 \mathrm{~m}$, diameter: $1.3 \mathrm{~m}$, circumference: $4.1 \mathrm{~m}$, a float controlling the water level) also had a circular mown patch $\left(78 \mathrm{~m}^{2}\right)$ and painted circle around it (radius: $\left.4.5 \mathrm{~m}\right)$ to quantify the time spent in this area.

\section{Environmental Variables}

Air temperature and relative humidity (HMP45A humidity and temperature sensor, Vaisala, Helsinki, Finland), wind speed (\# 40 Hall effect anemometer, NRG Systems, Hinesburg, VT), rainfall (tipping spoon rain gauge, Pronamic Silkeborg, Denmark), solar radiation (Li-Cor Li200x Pyranometer, Campbell Scientific Inc., Logan, UT), and black globe temperature (BGT, CSI 107 temperature sensor in black ball, Campbell Scientific Inc.) were recorded at 10-min intervals with a data logger (CR10X, Campbell Scientific Inc.) on a weather station located near the no-shade treatment. The microclimate (temperature, humidity, BGT) was measured underneath the structures in the shade treatments with Hobo Pro Dataloggers (Onset Computer Corp., Bourne, MA). Three Hobo data loggers were used during the experiment and these were rotated between groups (1 Hobo in each treatment at any 1 time). The logger in the no-shade treatment failed on several occasions, thus the estimates of weather in this treat- 
ment group were collected from the weather station described above. The temperature-humidity index (THI; Igono et al., 1992) and heat load index (HLI, modified after Castanẽda et al., 2004) were used as indicators of thermal comfort and calculated as follows:

$$
\begin{gathered}
\mathrm{THI}=(1.8 \times T+32)-[(0.55-0.0055 \times \mathrm{RH}) \\
\times(1.8 \times T-26)], \\
\mathrm{HLI}=\mathrm{IF}[\mathrm{BGT}>25,8.62+(0.38 \times \mathrm{RH}) \\
+(1.55 \times \mathrm{BGT})+\exp (-\mathrm{WS}+2.4)-0.5 \times \mathrm{WS}, \\
10.66+(0.28 \times \mathrm{RH})+(1.3 \times \mathrm{BGT})-\mathrm{WS}],
\end{gathered}
$$

where $T=$ air temperature $\left({ }^{\circ} \mathrm{C}\right), \mathrm{RH}=$ relative humidity $(\%), \mathrm{BGT}=$ black globe temperature $\left({ }^{\circ} \mathrm{C}\right)$, and $\mathrm{WS}=$ wind speed $(\mathrm{m} / \mathrm{s})$. Part of an Excel (Microsoft, Redmond, WA) formula, IF indicates that if the BGT value is larger than 25 , then the value 8.62 should be used in the formula.

\section{Behavior}

Time budgets for lying, standing, and grazing behavior were recorded with instantaneous scan sampling (Martin and Bateson, 1993) every $10 \mathrm{~min}$ from 1000 to $1550 \mathrm{~h}$ on all $20 \mathrm{~d}$ of data collection. Cows were considered lying if their flank was in contact with the ground and standing if not. Cows were considered grazing if feed was being ingested or could be seen in the mouth. Furthermore, the use of the shade structures and proximity to the water trough were recorded with 10-min instantaneous scan sampling. The use of the shade structures was measured in 2 ways to account for the movement of shade throughout the day. First, if at least 1 hoof was on or within the painted rectangle directly beneath the shade structure, this signified a shade event. Second, if at least 1 hoof was within the shadow cast by the structure, this signified a shade event. This second measurement was only taken when the outline of the shadow was clearly defined on all 4 sides of the structure $(58 \%$ of the observations, daily mean, range: 0 to $100 \%$ ). Both measures were used because recording only the latter would result in an underestimation of shade use when the shadow was not clearly visible. Total time spent using the shade structures was calculated using a combination of the 2 measures of shade use: if cows had at least 1 hoof either directly underneath the structure or in the shadow cast by the structure. Use of the area near the water trough was recorded when at least any 2 hooves were within the painted circle $(4.5-\mathrm{m}$ radius) around the trough.
Aggressive interactions beneath the shade were recorded continuously between 1000 and $1550 \mathrm{~h}$ in the 2.4 $\mathrm{m}^{2}$ and $9.6 \mathrm{~m}^{2}$ treatments. An aggressive interaction was defined as the contact between any part of one cow (the instigator; head or shoulder or both simultaneously) and another cow that resulted in immediate hoof movement (e.g., stepping sideways or away from the instigator). At least 1 of the cows involved in the aggressive interaction had to be within the painted rectangle of the shade structure to score the event. The identity of each individual involved in aggressive interactions was not recorded; thus, the values are expressed as the total number of interactions per group within $5.8 \mathrm{~h}$.

For all other behavioral measures, individual cows were identified with colored collars and paint on the shoulders and rump (Tell tail paint, FIL NZ Ltd., Mount Maunganui, New Zealand). A single observer watched 1 group of cows at any given time. Thus, multiple observers were used to collect the behavioral information from all groups. Interobserver reliability for the scan observations, as measured by percentage agreement, was between 97 and $100 \%$ for all behaviors. Interobserver agreement was lowest when assessing time spent grazing. The interobserver reliability for aggressive interactions, as measured by correlation, was 1.0.

\section{Physiological Measurements}

Internal body temperature was recorded every 10 min using a modified vaginal controlled internal drug release insert (CIDR, InterAg, Hamilton, New Zealand) fitted with a microprocessor-controlled MinilogTX data logger (Vemco Ltd., Shad Bay, Nova Scotia, Canada). Temperature loggers were inserted into the vaginal cavity $24 \mathrm{~h}$ before the first observation and removed immediately after the $5 \mathrm{~d}$ of observation $(20 \mathrm{~d}$ of data collection in total). Four cows had some amount of unusable data caused by logger failure (2 cows in the $2.4 \mathrm{~m}^{2}$ and $9.6 \mathrm{~m}^{2}$ treatments, respectively) and were entirely excluded from the analysis of body temperature. We examined the mean and maximum body temperature for the period between 1000 and $1550 \mathrm{~h}$.

Respiration rate was recorded once per hour for each cow between 1000 to $1550 \mathrm{~h}$ on all $20 \mathrm{~d}$ of data collection, resulting in 30 recordings per cow $(6$ recordings/d for $5 \mathrm{~d} /$ cow). Cows were video recorded for $1 \mathrm{~min}$ using a Sony Digital Handycam (DCR-TRV355E PAL with a $700 \times$ digital zoom, Sony, Japan) when they were standing still, without grazing, or lying down. Video recordings were analyzed by 2 observers at the conclusion of the study. Respiration rate per minute was calculated by counting the number of rises of the flank for $30 \mathrm{~s}$ and then converting to breaths/min to facilitate comparison with other studies. Because of animals moving, it was 
Table 1. Summary of meteorological records for the 20-d experiment in summer during the observation period (1000 to $1550 \mathrm{~h}$ ) and over $24 \mathrm{~h}$ in the different treatments

\begin{tabular}{|c|c|c|c|c|c|c|c|c|}
\hline \multirow[b]{2}{*}{ Weather variable } & \multicolumn{2}{|c|}{$\begin{array}{l}\text { No shade } \\
(24 \mathrm{~h})\end{array}$} & \multicolumn{2}{|c|}{$\begin{array}{c}\text { No shade } \\
(1000 \text { to } 1550 \mathrm{~h})\end{array}$} & \multicolumn{2}{|c|}{$\begin{array}{l}2.4 \mathrm{~m}^{2} \text { shade } / \mathrm{cow} \\
(1000 \text { to } 1550 \mathrm{~h})\end{array}$} & \multicolumn{2}{|c|}{$\begin{array}{c}9.6 \mathrm{~m}^{2} \text { shade } / \mathrm{cow} \\
(1000 \text { to } 1550 \mathrm{~h})\end{array}$} \\
\hline & Mean & Range & Mean & Range & Mean & Range & Mean & Range \\
\hline Air temperature $\left({ }^{\circ} \mathrm{C}\right)$ & 18 & $5-28$ & 22 & $16-28$ & 23 & $17-30$ & 22 & $16-28$ \\
\hline Black globe temperature $\left({ }^{\circ} \mathrm{C}\right)$ & 21 & $4-44$ & 30 & $18-44$ & 25 & $17-33$ & 23 & $16-30$ \\
\hline Relative humidity (\%) & 72 & 39-94 & 59 & $40-87$ & 59 & $36-96$ & 62 & 40-94 \\
\hline Solar radiation $\left(\mathrm{W} / \mathrm{m}^{2}\right)$ & 261 & $0-1,243$ & 704 & $67-1,243$ & $\mathrm{NA}^{1}$ & NA & NA & NA \\
\hline Temperature-humidity index & 63 & $42-75$ & 69 & $60-75$ & 69 & $62-78$ & 68 & $60-74$ \\
\hline Heat load index & 62 & $38-104$ & 78 & $53-103$ & NA & $\mathrm{NA}$ & NA & NA \\
\hline
\end{tabular}

${ }^{1} \mathrm{NA}=$ not applicable.

not possible to obtain respiration rate for 15,17 , and $17 \%$ of the observations for the no-shade, $2.4 \mathrm{~m}^{2}$, and $9.6 \mathrm{~m}^{2}$ treatments, respectively. Interobserver reliability for respiration rate, as measured by correlation, was 0.99. Finally, daily milk production was recorded for all treatment groups.

\section{Statistical Analysis}

Groups served as the experimental unit. All data for each group were averaged per week ( $5 \mathrm{~d}$ of testing per group, 3 groups tested simultaneously, 1 of each treatment, $\mathrm{n}=4$ groups/treatment). The effect of the amount of shade (2 df) and week (3 df) of the experiment was analyzed using ANOVA. Because this design explored the dose-response relationship for amount of shade, the linear response to the treatment (1 df) was tested against the same error term (6 df). Behaviors considered in the statistical analysis included time spent grazing, lying, standing, standing without grazing, near the water trough (within $4.5 \mathrm{~m}$ of water), and in the shade, and the number of aggressive interactions. The latter was expressed as total number of interactions and interactions per square meter of shade. Physiological variables considered in the statistical analysis were body temperature (mean and maximum values for period from 1000 to $1550 \mathrm{~h}$ ), respiration rate, and milk production. Normality and homoscedasticity of the residuals were examined for all variables. All variables were analyzed without transformation except for aggressive interactions; in this case, rank transformation was used. One cow in the $9.6 \mathrm{~m}^{2}$ shade/cow treatment developed mastitis and all values for this cow were omitted from all statistical analyses. Finally, $3 \mathrm{~d}$ of shade use were lost in the $9.6 \mathrm{~m}^{2}$ shade/cow treatment because of observer error.

The effect of the amount of shade on the behavioral and physiological responses to weather was analyzed using a mixed model (with random terms for week and day within week) using data for each group on each day. The relationship between milk production and weather was not investigated because the animals were provided supplemental feed, thus milk production increased for all groups during the first days of testing. Behavioral and physiological data were averaged for each group and day. The weather data (air temperature, BGT, relative humidity, solar radiation, THI, and HLI) were averaged for each day (1000 to $1550 \mathrm{~h}$ ). We examined the effect of the amount of shade provided on the relationship between the behavioral and physiological variables and the weather variables, and tested whether these relationships were affected by treatment. All statistical analyses were conducted using the statistical package GenStat, version 10.2 (VSN International, Hemel Hempstead, UK).

\section{RESULTS}

\section{Environmental Conditions}

Air temperature, BGT, wind speed, rainfall, relative humidity, and solar radiation recordings during the experiment and calculated THI and HLI values are summarized in Table 1. Ambient temperature, solar radiation, HLI, and THI are all different measures of heat load, and results were presented with all 4 weather variables to facilitate comparison with other research.

\section{Behavior}

The cows with access to $9.6 \mathrm{~m}^{2}$ shade/cow spent more than twice as much time in the shade compared with cows with access to $2.4 \mathrm{~m}^{2}$ shade/cow (50 vs. $24 \%$ of $5.8 \mathrm{~h}$ of observation, respectively, Table 2). Daily shade use across the 20-d study is shown in Figure 1. Both groups with access to shade spent more time in the shade with increasing heat load (Table 3, Figure 2 ). Furthermore, cows with $9.6 \mathrm{~m}^{2}$ of shade/cow spent less time around the water trough than the cows with 
Table 2. Behavior, body temperature, respiration rate, and milk production (mean values) of dairy cows with access to $2.4 \mathrm{~m}^{2}$ shade/cow, 9.6 $\mathrm{m}^{2}$ shade/cow, or no shade during $20 \mathrm{~d}$ of observation ( $\mathrm{n}=4$ groups/treatment, 10 cows/group) in summer

\begin{tabular}{|c|c|c|c|c|c|c|}
\hline Variable & No shade & $\begin{array}{c}2.4 \mathrm{~m}^{2} \\
\text { shade/cow }\end{array}$ & $\begin{array}{c}9.6 \mathrm{~m}^{2} \\
\text { shade/cow }\end{array}$ & $\mathrm{SED}^{1}$ & $P$-value ${ }^{2}$ & $P$-value ${ }^{3}$ \\
\hline In shade $(\mathrm{h} / 5.8 \mathrm{~h})$ & - & 1.4 & 2.9 & 0.10 & $<0.001$ & - \\
\hline Grazing (h/5.8 h) & 2.3 & 2.3 & 2.1 & 0.20 & 0.501 & 0.259 \\
\hline Standing, without grazing $(\mathrm{h} / 5.8 \mathrm{~h})$ & 2.5 & 2.7 & 2.9 & 0.19 & 0.229 & 0.108 \\
\hline Aggressive interactions in shade (no. per $5.8 \mathrm{~h}$ ) & - & 25.7 & 30.9 & 1.61 & 0.014 & - \\
\hline Maximum body temperature $\left({ }^{\circ} \mathrm{C}\right)$ & 39.8 & 39.3 & 39.5 & 0.31 & 0.441 & 0.555 \\
\hline Respiration rate (breaths/min) & 62 & 57 & 51 & 2.13 & 0.007 & 0.003 \\
\hline Milk production (L/d) & 18.8 & 18.5 & 18.2 & 0.26 & 0.205 & 0.095 \\
\hline
\end{tabular}

${ }^{1}$ Standard error of the difference between treatments.

${ }^{2} P$-value for the difference between treatments.

${ }^{3} P$-value for the linear term.

$2.4 \mathrm{~m}^{2}$ or no shade (Table 2). Cows spent more time around the water trough as heat load increased, and this relationship was more pronounced when the cows had access to only $2.4 \mathrm{~m}^{2}$ or no shade (Table 3, Figure $3)$. There were no treatment differences in time spent grazing, standing without grazing, or lying (Table 2).
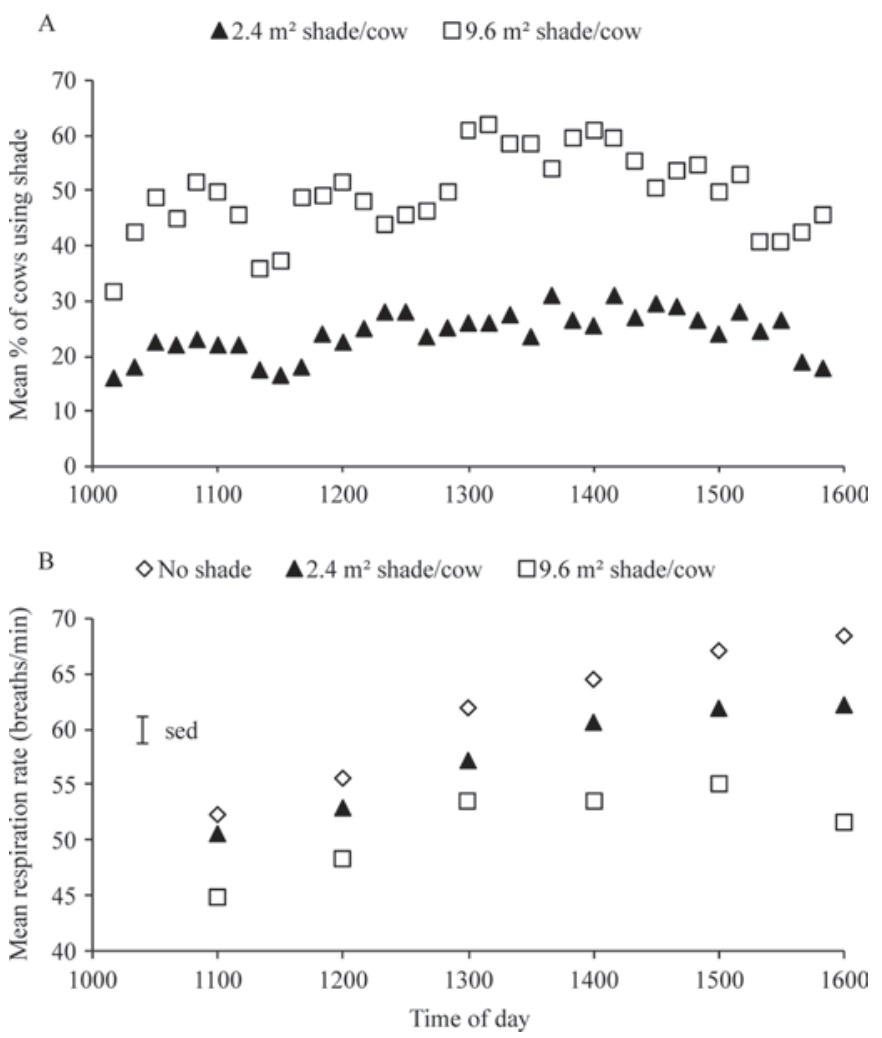

Figure 1. Relationship between mean percentage of cows using the shade (A) and mean respiration rate (B) and time of day (20 d in total) of dairy cows with no access to shade, or access to $2.4 \mathrm{~m}^{2}$ or 9.6 $\mathrm{m}^{2}$ shade/cow at pasture $(1000$ to $1550 \mathrm{~h})$ in summer $(\mathrm{n}=4$ groups per treatment, 10 cows/group, $5 \mathrm{~d} /$ group).
Standing without grazing was the most common behavior beneath the shade, but the cows spent some time lying in the shade $(4 \pm 1.8$ and $17 \pm 7.2 \mathrm{~min} / 5.8$ $\mathrm{h}$ for $2.4 \mathrm{~m}^{2}$ and $9.6 \mathrm{~m}^{2}$ shade/cow, respectively, mean $\pm \mathrm{SE})$. All groups spent less time lying and more time standing without grazing with increasing heat load (Table 3). There was no overall difference in total lying time between the 2 shade treatments. Cows with access to $9.6 \mathrm{~m}^{2}$ shade/cow used the shade simultaneously, whereas the groups with $2.4 \mathrm{~m}^{2}$ shade/cow were never observed using the shade at the same time. For example, simultaneous use was observed in 15 versus $0 \%$ of observations on the day of the experiment with highest HLI (HLI $=95$, THI $=72$, air temperature $=$ $24.9^{\circ} \mathrm{C}$ ) for the cows in the 9.6 and $2.4 \mathrm{~m}^{2}$ shade/cow treatment, respectively. Simultaneous use increased with HLI (Figure 4), and the mean percentage of cows in shade per day was higher when more shade was provided $\left(87\right.$ and $56 \%$ for the $9.6 \mathrm{~m}^{2}$ and $2.4 \mathrm{~m}^{2}$ treatments, respectively, SED: $3.1 \%$; $P<0.001$ ). Aggressive interactions were more common in the $9.6 \mathrm{~m}^{2}$ treatment than in the $2.4 \mathrm{~m}^{2}$ shade/cow treatment (Table 2). The larger shade area increased the probability of observing aggressive interactions; when this is taken into account, aggressive interactions were more common in the 2.4 $\mathrm{m}^{2}$ treatment (Table 2), and this is the trait explored in the remainder of the results and discussion. Cows engaged in more aggressive interactions in the shade as heat load increased, particularly if they had less shade (Table 3, Figure 5).

\section{Physiology}

Cows had higher respiration rates in the treatments with less or no shade (Table 2, Figure 1). There was no overall effect of treatment on any of the body temperature variables (mean or maximum, Table 2) during 
the observation period (1000 to $1550 \mathrm{~h}$ ) or on milk production (Table 2).

Weather influenced respiration rate and body temperature. Respiration rate and body temperature increased with increasing heat load (Table 3). The increase in respiration rate and body temperature was more pronounced in the $2.4 \mathrm{~m}^{2}$ and no-shade treatments (Figure 6).

\section{DISCUSSION}

Cows with access to $9.6 \mathrm{~m}^{2}$ shade/cow spent more than twice as much time in the shade as cows with 2.4 $\mathrm{m}^{2}$ shade/cow (2.9 and $1.4 \mathrm{~h} / 5.8 \mathrm{~h}$, respectively). Shade use increased with solar radiation and HLI, supporting results of other studies (Bennett et al., 1984-1985; Tucker et al., 2008; Schütz et al., 2009). As shade becomes more important (i.e., heat load increases), cattle are more likely to compete for this resource. Dairy cows are highly motivated to use shade in hot weather (Schütz et al., 2008), and the results from the present study provide further evidence that shade is a valuable resource for dairy cattle in summer.

In addition to cows spending more time under the larger shade structure, the use of the shade changed between treatments. When $9.6 \mathrm{~m}^{2}$ shade/cow was provided, cows were able to use it simultaneously and there were $70 \%$ fewer aggressive interactions than in the 2.4 $\mathrm{m}^{2}$ treatment when the size of the area was taken into account. Similarly, cows with $9.6 \mathrm{~m}^{2}$ shade/cow spent a higher proportion of their lying time in the shade than cows with $2.4 \mathrm{~m}^{2}$ shade (36 and $10 \%$, respectively). Simultaneous shade use and lying in the shade indicate that, if given more space, cows are able to share the resource rather than compete for it.

Although this work demonstrated that the amount of shade influenced the effectiveness of this resource, additional information is needed to make specific recommendations about the amount of shade needed for a given group size. In the meantime, enough shade should be provided that cows can use the shade simultaneously, especially when heat load is highest. Treatment differences in shade use were apparent when HLI was $<70$ (mean air temperature on days with HLI of 69 to 71 ranged between 19 and $23^{\circ} \mathrm{C}$ ). Cows in the $2.4 \mathrm{~m}^{2}$ treatment began to compete actively for shade and cows without shade began to spend more time around the water trough when HLI was approximately 75 (mean air temperature on days with HLI of 74 to 76 ranged between 19 and $25^{\circ} \mathrm{C}$ ). In addition, lower respiration rates were found in the $9.6 \mathrm{~m}^{2}$ treatment when HLI was 65 (mean air temperature on days with HLI of 64 to 66 ranged between 20 and $21^{\circ} \mathrm{C}$ ), indicating that shade was likely beneficial for cattle in cooler weather. 


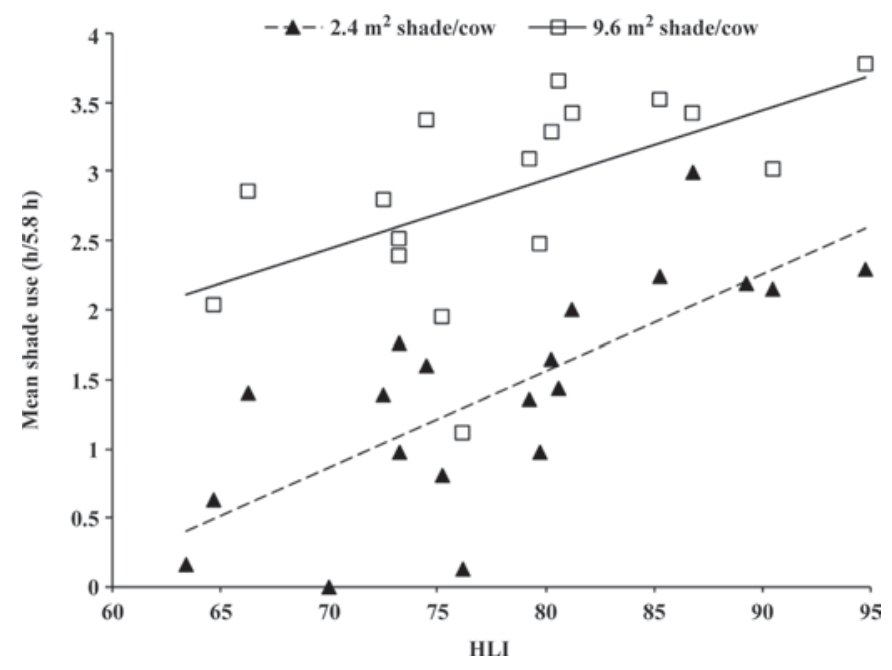

Figure 2. Relationship between mean time spent in shade and heat load index (HLI) of dairy cows with access to $2.4 \mathrm{~m}^{2}$ or $9.6 \mathrm{~m}^{2}$ shade/ cow at pasture $(1000$ to $1550 \mathrm{~h})$ in summer $(\mathrm{n}=4$ groups per treatment, 10 cows/group, $5 \mathrm{~d} /$ group).

When heat load is high, animals change their behavior to cool down. For example, cows reduced lying time (Overton et al., 2002; Zähner et al., 2004) and grazing (Tucker et al., 2008) when heat load increased. All treatment groups in the present study spent less time lying and more time standing with increasing heat load, supporting previous findings, although there were no treatment differences in overall lying times. It has been suggested that cattle stand as a way to maximize the surface area exposed to the environment and increase the airflow around the body (e.g., Ansell, 1981). Cattle change grazing times and patterns to cope with heat load (Kendall et al., 2006), and this change is believed to contribute to decreased milk production (Roman-Ponce et al., 1977; Davison et al., 1988; Kendall et al., 2006). No treatment differences were found in grazing behavior or milk production. It is possible that the weather during the $5 \mathrm{~d}$ of observations per group was not warm enough to reduce milk production or change grazing behavior (mean air temperature was $22^{\circ} \mathrm{C}$, range: 16 to $28^{\circ} \mathrm{C}$ during daytime), and the length of the measurement period ( $5 \mathrm{~d}$, behavior measured only during the hottest part of the day) was likely insufficient to detect any differences in milk production or meaningful shifts in grazing patterns. Finally, cows were supplemented with silage, making feed relatively easy to obtain, and this may have changed the energetic trade-offs for intake.

Cattle also reduce the effects of high heat load by increasing water consumption (Muller et al., 1994a). Access to cooled drinking water $\left(18.3\right.$ vs. $\left.31.2^{\circ} \mathrm{C}\right) \mathrm{im}-$ proved weight gain in feedlot cattle in summer (mean air temperature: $29.7^{\circ} \mathrm{C}$; Ittner et al., 1951), and several studies have shown that beef cattle increase their water consumption and spend more time around the water trough in summer, particularly when there is no access to shade (Mader et al., 1997; Widowski, 2001). In the current study, cows without shade spent more time around the water trough than cows with access to 9.6 $\mathrm{m}^{2}$ shade/cow. These results support those of Mader et al. (1997), where the percentage of beef cattle around the water trough was 2 to 3 times greater for unshaded groups than for groups with more than $3.5 \mathrm{~m}^{2}$ shade/ animal, especially during peak heat load. In the current study, time around the water trough increased with heat load, and this behavioral change was more pronounced in the groups with less and no shade when HLI was $>70$. Cattle may increase time around the water trough for several reasons. Evaporation from the water may create a cooler microclimate. Alternatively, cows may spend more time near the water because they are drinking more water overall or drinking more frequently. Regardless of why cattle congregate around the water trough, there are practical implications of aggregation of animals around a specific resource such as shade or water. Our findings show that cows will spend a large proportion of the day in the shade when given access to it, but cows with less or no shade will instead congregate around the water, which may cause similar pasture damage.

Cows with access to $9.6 \mathrm{~m}^{2}$ shade/cow spent more time in the shade and less time around the water trough and experienced a lower heat load. This idea is supported by lower respiration rates in this group $(51,57$, and 62 breaths/min for $9.6 \mathrm{~m}^{2}$ shade/cow, $2.4 \mathrm{~m}^{2}$ shade/cow, and no shade, respectively). There was no difference

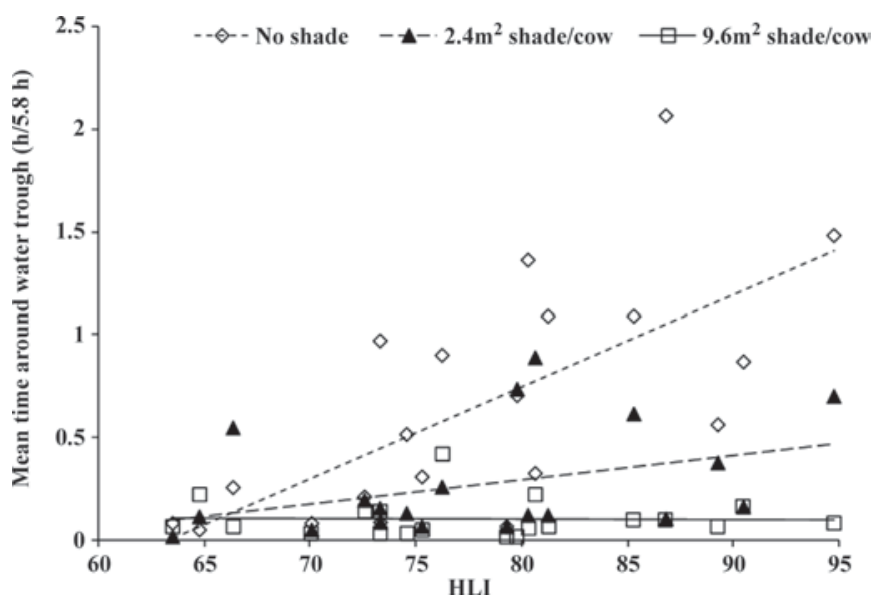

Figure 3. Relationship between mean time spent around the water trough and heat load index (HLI) of dairy cows with no access to shade, or access to $2.4 \mathrm{~m}^{2}$ or $9.6 \mathrm{~m}^{2}$ shade/cow at pasture (1000 to $1550 \mathrm{~h}$ ) in summer $(\mathrm{n}=4$ groups per treatment, 10 cows/group, $5 \mathrm{~d}$ / group). 


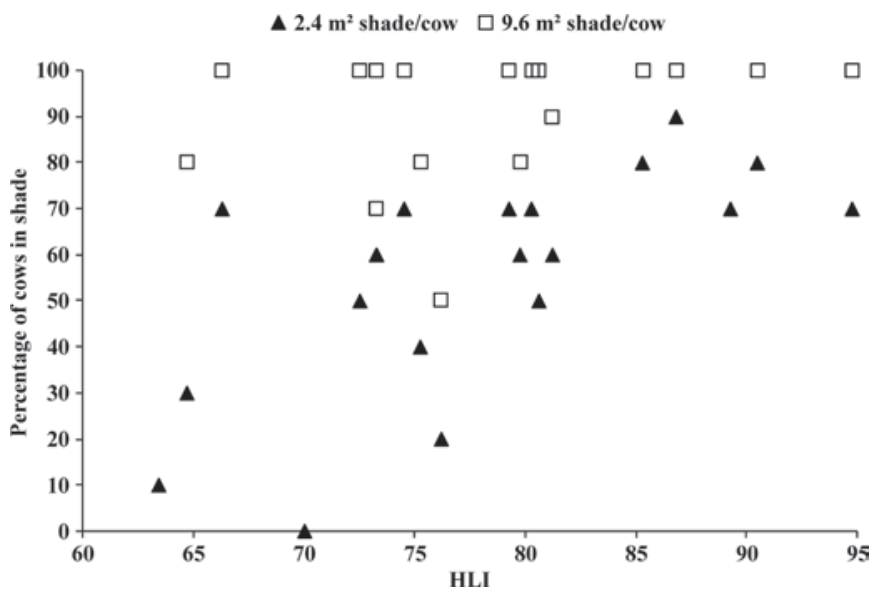

Figure 4. Maximum number of dairy cows (\%) using the shade simultaneously on days with different heat load indices (HLI, mean/d). The cows had access to $2.4 \mathrm{~m}^{2}$ or $9.6 \mathrm{~m}^{2}$ shade/cow at pasture (1000 to $1550 \mathrm{~h}$ ) in summer ( $\mathrm{n}=4$ groups per treatment, 10 cows/group, 5 d/group).

in mean body temperature between treatments. The body temperature results in the current study (mean body temperature was $38.5^{\circ} \mathrm{C}$ for the no-shade treatment and $38.4^{\circ} \mathrm{C}$ for both shade treatments) are similar to values from cows with and without shade in the same study area (mean body temperatures of 38.7 and $38.6^{\circ} \mathrm{C}$ for cows without vs. with shade; Kendall et al., 2006; Tucker et al., 2008). There were treatment differences in how respiration rate and body temperature responded to weather. As in other studies, both respiration rate and body temperature increased with heat load (air temperature, solar radiation, THI, and HLI;

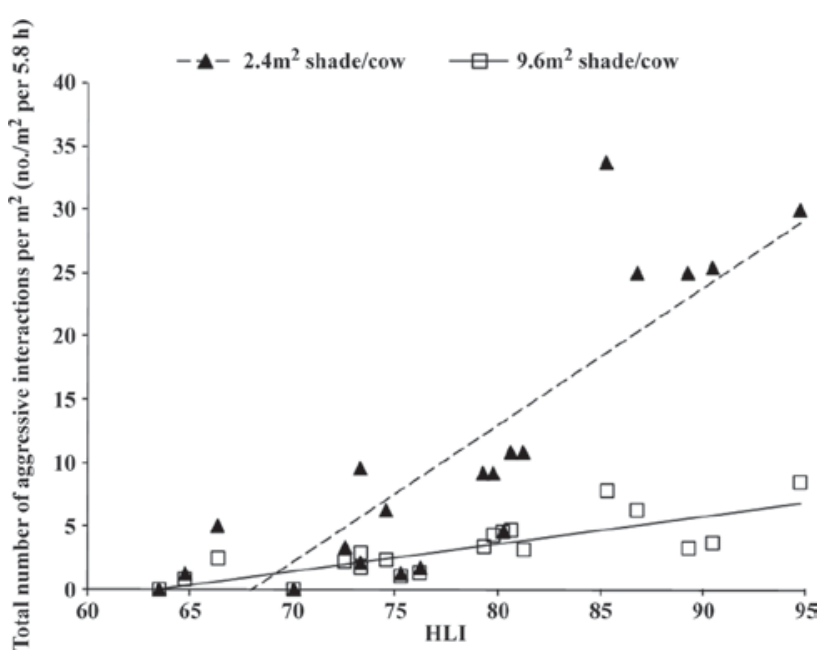

Figure 5. Total number of aggressive interactions per square meter during $5.8 \mathrm{~h}$ of observation in shade in relation to heat load index (HLI) of dairy cows. The cows had access to $2.4 \mathrm{~m}^{2}$ or $9.6 \mathrm{~m}^{2}$ shade/ cow at pasture (1000 to $1550 \mathrm{~h})$ in summer $(\mathrm{n}=4$ groups per treatment, 10 cows/group, $5 \mathrm{~d}$ /group).
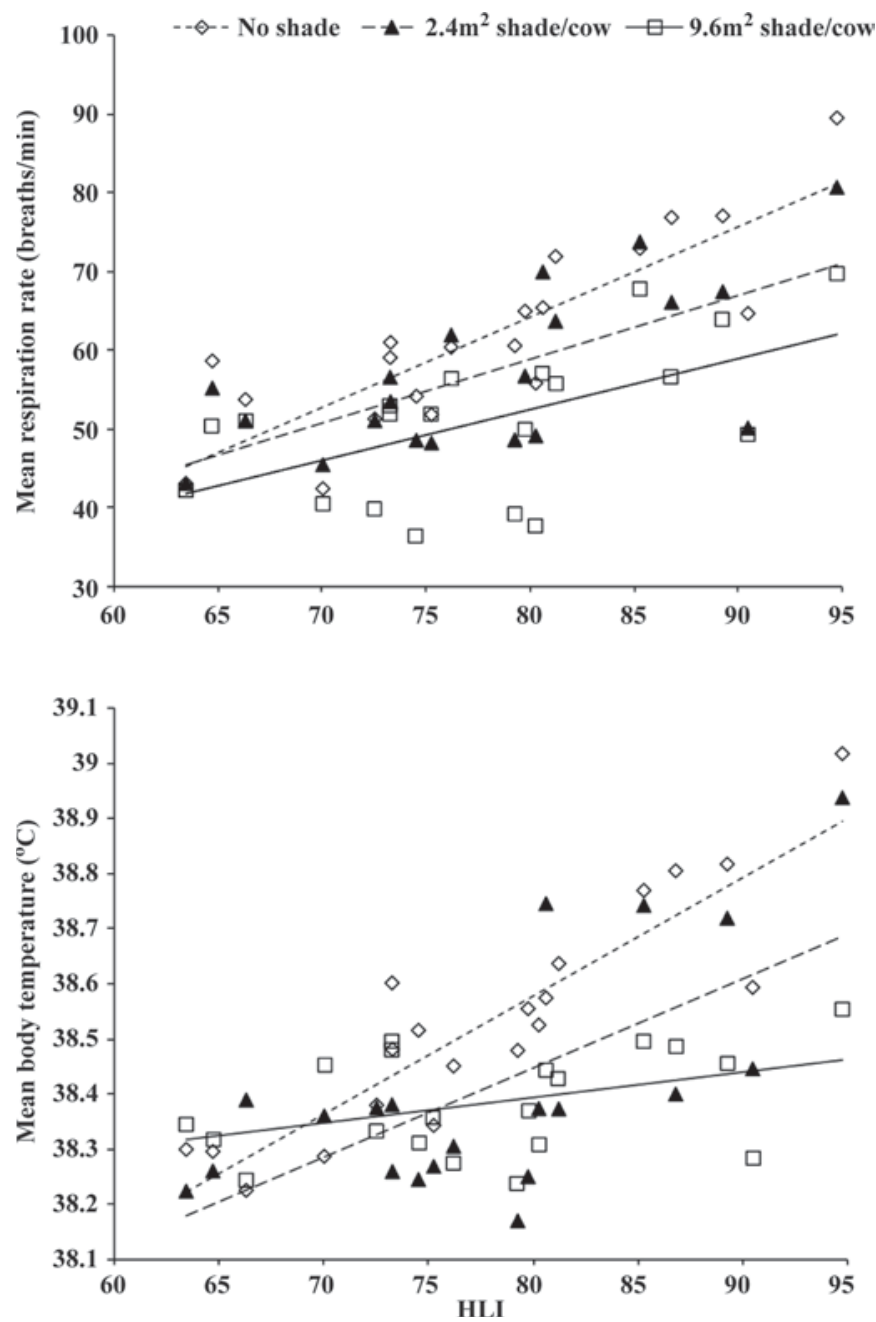

Figure 6. Relationship between heat load index (HLI) and mean respiration rate (top) and body temperature (bottom) of dairy cows with no access to shade or access to $2.4 \mathrm{~m}^{2}$ or $9.6 \mathrm{~m}^{2}$ shade/cow at pasture (1000 to $1550 \mathrm{~h})$ in summer ( $\mathrm{n}=4$ groups per treatment, 10 cows/group, $5 \mathrm{~d}$ /group).

e.g., Muller et al., 1994b; Kendall et al., 2007; Schütz et al., 2009). This increase was more marked in the 2.4 $\mathrm{m}^{2}$ shade/cow and no-shade treatments than in the 9.6 $\mathrm{m}^{2}$ shade/cow treatment. These results indicate that cattle use shade to prevent an increase in internal body temperature, but this heat mitigation strategy is only effective if a sufficient amount of shade is provided.

\section{CONCLUSIONS}

Providing a greater area of shade to dairy cattle increased the time spent in the shade and allowed simultaneous use of the shade. Cattle with access to more shade showed reduced physiological and behavioral responses to heat, namely respiration rate and less time around the water trough. The benefits of a larger 
amount of shade were more pronounced with increasing heat load. Cattle will use shade to prevent increased body temperature, but this behavioral mitigation strategy is only effective if enough shade is provided. These findings highlight the importance of determining the appropriate design and amount of shade for larger groups of cattle.

\section{ACKNOWLEDGMENTS}

We gratefully acknowledge the technical assistance from all observers and AgResearch staff: Kate Clark, Michelle Donald, Suzanne Dowling, James EvansMcLeod, Nicola Haworth, Frankie Huddart, Paul Kendall, Leanne McPake, Julia Oh, Renee Railton, Haley Shepherd, Else Verbeek, Jordan van der Wel, Talia van der Wel, Gemma Worth, and Anna Holten. We are grateful to the staff at AgResearch No. 1 and 2 dairies and to Kevin Orr and Ron Clarke. This work was funded by DairyNZ (Hamilton, New Zealand) and by the Foundation for Research, Science and Technology (Wellington, New Zealand).

\section{REFERENCES}

Ansell, R. H. 1981. Extreme heat stress in dairy cattle and its alleviation: A case report. Pages 285-306 in Environmental Aspects of Housing for Animal Protection. J. A. Clark, ed. Butterworths, London, UK.

Armstrong, D. V. 1994. Heat stress interaction with shade and cooling. J. Dairy Sci. 77:2044-2050.

Bennett, I. L., V. A. Finch, and C. R. Holmes. 1984-1985. Time spent in shade and its relationship with physiological factors of thermoregulation in three breeds of cattle. Appl. Anim. Behav. Sci. $13: 227-236$

Buffington, D. E., R. J. Collier, and G. H. Canton. 1983. Shade management systems to reduce heat stress for dairy cows in hot, humid climates. Trans. ASAE 26:1798-1802.

Castanẽda, C. A., J. B. Gaughan, and Y. Sakaguchi. 2004. Relationships between climatic conditions and the behaviour of feedlot cattle. Proc. Aust. Soc. Anim. Prod. 25:33-36.

Collier, R. J., G. E. Dahl, and M. J. VanBaale. 2006. Major advances associated with environmental effects on dairy cattle. J. Dairy Sci. 89:1244-1253.

Davison, T. M., B. A. Silver, A. T. Lisle, and W. N. Orr. 1988. The influence of shade on milk production of Holstein-Friesian cows in a tropical upland environment. Aust. J. Exp. Agric. 28:149-154.

De Rensis, F., and R. J. Scaramuzzi. 2003. Heat stress and seasonal effects on reproduction in the dairy cow-A review. Theriogenology 60:1139-1151.

Garrett, W. N., C. F. Kelly, and T. E. Bond. 1962. Total and shaded space allotments for beef feedlots as affected by ration in a high temperature environment. J. Anim. Sci. 21:794-797.

Hahn, G. L. 1999. Dynamic responses of cattle to thermal heat loads. J. Anim. Sci. 77:10-20.

Igono, M. O., G. Bjotvedt, and H. T. Sanford-Crane. 1992. Environmental profile and critical temperature effects on milk production of Holstein cows in desert climate. Int. J. Biometeorol. $36: 77-87$.
Ittner, N. R., T. E. Bond, and C. F. Kelly. 1954. Increasing summer gains of livestock: With cool water, concentrate roughage, wire corrals, and adequate shades. J. Anim. Sci. 13:867-877.

Ittner, N. R., C. F. Kelly, and H. R. Guilbert. 1951. Water consumption of Hereford and Brahman cattle and the effect of cooled drinking water in a hot climate. J. Anim. Sci. 10:742-751.

Kendall, P. E., P. P. Nielsen, J. R. Webster, G. A. Verkerk, R. P. Littlejohn, and L. R. Matthews. 2006. The effects of providing shade to lactating dairy cows in a temperate climate. Livest. Sci. 103:148-157.

Kendall, P. E., G. A. Verkerk, J. R. Webster, and C. B. Tucker. 2007. Sprinklers and shade cool cows and reduce insect-avoidance behavior in pasture-based dairy systems. J. Dairy Sci. 90:36713680 .

Mader, T. L., L. R. Fell, and M. J. McPhee. 1997. Behavior response of non-Brahman cattle to shade in commercial feedlots. Livest. Environ. 5:795-802.

Martin, P., and P. Bateson. 1993. Measuring Behaviour. An Introductory Guide. 2nd edition. Cambridge University Press, Cambridge, UK.

Muller, C. J. C., J. A. Botha, W. A. Coetzer, and W. A. Smith. 1994b. Effect of shade on various parameters of Friesian cows in a Mediterranean climate in South Africa. 2. Physiological responses. S. Afr. J. Anim. Sci. 24:56-60.

Muller, C. J. C., J. A. Botha, and W. A. Smith. 1994a. Effect of shade on various parameters of Friesian cows in a Mediterranean climate in South Africa. 1. Feed and water intake, milk production and milk composition. S. Afr. J. Anim. Sci. 24:49-55.

Ominski, K. H., A. D. Kennedy, K. M. Wittenberg, and S. A. Moshtaghi-Nia. 2002. Physiological and production responses to feeding schedule in lactating dairy cows exposed to short-term, moderate heat stress. J. Dairy Sci. 85:730-737.

Overton, M. W., W. M. Sischo, G. D. Temple, and D. A. Moore. 2002. Using time-lapse video photography to assess dairy cattle lying behavior in a free-stall barn. J. Dairy Sci. 85:2407-2413.

Roman-Ponce, H., W. W. Thatcher, D. E. Buffington, C. J. Wilcox, and H. H. Van Horn. 1977. Physiological and production responses of dairy cattle to a shade structure in a subtropical environment. J. Dairy Sci. 60:424-430.

Schütz, K. E., N. R. Cox, and L. R. Matthews. 2008. How important is shade to dairy cattle? Choice between shade or lying following different levels of lying deprivation. Appl. Anim. Behav. Sci 114:307-318.

Schütz, K. E., A. R. Rogers, N. R. Cox, and C. B. Tucker. 2009. Dairy cows prefer shade that offers greater protection against solar radiation in summer: Shade use, behaviour, and body temperature. Appl. Anim. Behav. Sci. 116:28-34.

Tucker, C. B., A. R. Rogers, and K. E. Schütz. 2008. Effect of solar radiation on dairy cattle behaviour, use of shade and body temperature in a pasture-based system. Appl. Anim. Behav. Sci. 109:141-154

Valtorta, S. E., P. E. Leva, and M. R. Gallardo. 1997. Evaluation of different shades to improve dairy cattle well-being in Argentina. Int. J. Biometeorol. 41:65-67.

West, J. W. 2003. Effects of heat-stress on production in dairy cattle. J. Dairy Sci. 86:2131-2144.

Widowski, T. 2001. Shade-seeking behavior of rotationally grazed cows and calves in a moderate climate. Pages 632-639 in Livestock Environment VI: Proceedings of the 6th International Symposium, Louisville, KY. R. R. Stowell, R. Bucklin, and R. W. Bottcher, ed. ASAE Publication Number 701P0201. ASAE, St. Joseph, MI.

Zähner, M., L. Schrader, R. Hauser, M. Keck, W. Langhans, and B Wechsler. 2004. The influence of climatic conditions on physiological and behavioural parameters in dairy cows kept in open stables. Anim. Sci. 78:139-147. 